\title{
Patterns of antiplatelet agent use in the US
}

Authors

Institutions
Vijay Kanakadandi ${ }^{1,2}$, Sravanthi Parasa ${ }^{1,2}$, Preetika Sihn ${ }^{1,2}$, Mandeep Singh ${ }^{1}$, Maria Giacchino ${ }^{2,3}$, Neil Gupta $^{4}$, Srinivas Gaddam ${ }^{5}$, Amit Rastogi ${ }^{1,2}$, Ajay Bansal ${ }^{1,2}$, John Petrini ${ }^{6}$, Prateek Sharma ${ }^{1}$

Institutions are listed at the end of article. submitted 21. August 2014 accepted after revision 8. September 2014

\section{Bibliography}

Dol http://dx.doi.org/ 10.1055/s-0034-1390750

Published online: 24.6 .2015

Endosc Int Open 2015; 03: E173-E178

(c) Georg Thieme Verlag KG Stuttgart · New York E-ISSN 2196-9736

\section{Corresponding author}

\section{Prateek Sharma, MD}

University of Kansas Medical

Center, Gastroenterology

3901 Rainbow Boulevard

Kansas City, Kansas, 66160

Fax: +1-816-922-3362

psharma@kumc.edu
Background: The American Society of Gastrointestinal Endoscopy (ASGE) published updated guidelines in 2009 to help endoscopists manage the treatment of their patients who have been prescribed antiplatelet therapy (APT).

Study aim: To assess the use of APT among endoscopists, and to identify factors guiding their use of APT while treating their patients.

Method: A survey questionnaire was distributed to endoscopists at two national meetings to assess their usage of APT while treating patients during the peri-endoscopic period.

Results: The survey was provided to 400 attendees of whom 239 (60\%) responded. Only $30 \%$ of respondents followed the ASGE guidelines for treating their patients and $26 \%$ percent of respondents withheld all APT before engaging in any patient procedure. Endoscopists' decisions appeared to be influenced by their own particular experiences rather than any specific APT usage guide-

\begin{tabular}{|c|c|}
\hline \multicolumn{2}{|c|}{$\begin{array}{l}\text { Abbreviations } \\
\nabla\end{array}$} \\
\hline APT & antiplatelet therapy \\
\hline ASGE & $\begin{array}{l}\text { American Society of Gastrointestinal } \\
\text { Endoscopy }\end{array}$ \\
\hline BSG & British Society of Gastroenterology \\
\hline ESGE & $\begin{array}{l}\text { European Society of Gastrointestinal } \\
\text { Endoscopy }\end{array}$ \\
\hline EUS & endoscopic ultrasound \\
\hline NSAID & non-steroidal anti-inflammatory drugs \\
\hline EGD & esophagogastroduodenoscopy \\
\hline ERCP & $\begin{array}{l}\text { endoscopic retrograde cholangiopan- } \\
\text { creatography }\end{array}$ \\
\hline FNA & fine needle aspiration \\
\hline IRB & Institutional Review Board \\
\hline PEG & percutaneous enterogastric tube \\
\hline
\end{tabular}

lines (46\% vs $22 \%$; $P<0.05)$. As expected, more endoscopists $(P<0.05)$ continued APT for patients who underwent low risk procedures $(90 \%)$ than for patients who underwent high risk procedures (47\%). Approximately $50 \%$ of the respondents did not perform high risk procedures for patients prescribed aspirin therapy.

Conclusions: About one-fourth of endoscopists surveyed discontinued APT treatment of patients who underwent any endoscopic procedure, and one-half of them discontinued use of non-steroidal anti-inflammatory drug treatment of patients who underwent a high risk endoscopic procedure. Inappropriate withdrawal of APT medications may expose patients to unnecessary risks, and efforts to improve endoscopists' application of ASGE guidelines for the use of APT to treat patients during the peri-endoscopic period are warranted.

\section{Introduction}

Aspirin, thienopyridines (clopidrogrel and ticlopidine), and non-steroidal anti-inflammatory drugs (NSAIDs) are among the most commonly used drugs in the US [1]. Aspirin is recommended for the primary prevention of coronary artery disease [2,3] and is used by approximately $44 \%$ of patients at high risk of coronary artery disease [4]. NSAIDs are available over the counter and by prescription for the treatment of a variety of conditions. Approximately $20 \%$ of adults in the US have reported taking NSAIDs daily for at least one month [5].

Whereas aspirin and NSAIDs inhibit the cyclooxygenase pathway and thereby inhibit platelet aggregation, thienopyridines interfere with the glycoprotein IIb/IIIa receptor complex and prevent platelet aggregation, which affects bleeding time and can be a concern when patients undergo invasive testing. The concurrent use of these medi- 
cations at the time of endoscopy may increase the risk of periprocedural hemorrhage [6-9]. Hence, the procedural risk of bleeding must be weighed against the potential risk of thrombosis related to interruption of antiplatelet therapy (APT) during the peri-endoscopic period. In 1996, a survey performed among American Society of Gastrointestinal Endoscopy (ASGE) members revealed much variation in the management of APT in the peri-endoscopic period [10]. The ASGE, the British Society of Gastroenterology (BSG), and the European Society of Gastrointestinal Endoscopy (ESGE) have established consensus driven practice guidelines to help endoscopists manage patients on these drugs prior to endoscopic procedures [11-16].

There are some differences between the 2005 and 2009 ASGE guidelines [11, 12]. In the 2009 guidelines, therapeutic balloonassisted enteroscopy, endoscopic ultrasound (EUS) with fine needle aspiration (FNA), endoscopic hemostasis, tumor ablation by any technique, and cystogastrostomy have been identified as additional high risk procedures, whereas capsule endoscopy and endoscopic stent deployment have been identified as additional low risk procedures. Further, high and low risk conditions for thromboembolism have been identified to enable the endoscopists to make better informed decisions. Although specific guidelines were not mentioned, the 2009 ASGE document presents evidence about restarting APT after endoscopic hemostasis and elective endoscopy. Decision management algorithms were presented outlining the management of these drugs before endoscopy in elective and emergent settings.

Despite the publication of these guidelines, repeated surveys within the US and abroad have shown poor adherence to the recommendations and variation in the management of APT [1618]. No more recent survey detailing the practice patterns and adherence to recommendations among endoscopists in the US has been undertaken. We conducted this survey with the aim of assessing practice patterns among endoscopists and to identify factors responsible for them. In addition to shedding light on the practice of endoscopy, this study may help in refining future guidelines regarding the use of APT.

\section{Materials and methods}

\section{$\nabla$}

\section{Survey development}

A pilot survey was developed after reviewing the current literature and published guidelines, including the ASGE guidelines on management of APT [12]. The pilot survey was reviewed and pretested by three gastroenterologists. The feedback regarding the length, clarity, and content of the questions was discussed among the group and finally an antiplatelet management survey with 14 questions was drafted (Supplement). The study survey was conducted after it was approved by our institutional review board (IRB) committee.

\section{Survey}

The survey was conducted by distributing the questionnaire to attendees at the ASGE Endoscopy Course (Washington DC, USA) and the American College of Gastroenterology/ASGE Best Practices Course (Huntington Beach, CA). Participants were provided the survey when they checked in at the registration desk for the post-graduate course, and they were asked not to complete the survey if they had previously done so. The survey had three parts. The first part had three questions related to the practice of the endoscopist. The second part obtained information regarding the number and types of endoscopic procedures performed. The third part had nine questions detailing the endoscopists' practice of withholding antiplatelet agents during the peri-endoscopic period. Participants were allowed to choose more than one option in questions pertaining to the factors influencing the management of APT. Endoscopists' personal identifiers were not used when answering the questionnaire. There were no incentives paid for participating in the study.

\section{Data analysis}

Data gathered from the surveys was entered into a Microsoft Access database. Data was analyzed using IBM SPSS, Version 18.0. Chicago, IL. Chi-squared test and Fisher's exact test were done for univariate analyses. Covariates with $P$ value less than 0.1 were considered for multivariate logistic regression analysis. $P$ values less than 0.05 were considered statistically significant.

\section{Results \\ $\nabla$}

\section{Survey respondents}

The survey was provided to 400 attendees, of whom 239 (60\%) completed the survey. The median age of the endoscopists surveyed was 50 years, the median duration of practice was 15 years; respondents performed an average of 31 (95\%CI, 26) procedures per week. Only 71 (30\%) of the respondents claimed to follow the ASGE guidelines strictly for all procedures, 113 (47\%) were influenced by patient factors such as previous ischemic event or gastrointestinal bleed and 39 (16\%) used their own experience as a guide ( $\bullet$ Table 1 ).

\section{Withholding all APT}

Among the endoscopists surveyed, 26\% withheld all APT before any procedure ( Table 2 ). Their decision to withhold all APT appeared to stem from their own experience: $18 / 39$ (46\%) of those who used their own experience as a guide chose to withhold all APT compared to $41 / 188$ (22\%) who did not $(P<0.05)$. Notably, among those using their own experience, there was no significant difference in the number of physicians who witnessed ischemic or bleeding complications and no difference in the age group, number of procedures performed, or hospital type. In addition, witnessing gastrointestinal bleed in the past appeared to be a strong influence with 46/153 (30\%) who witnessed bleeding choosing to withhold all APT compared to $13 / 74$ (18\%) of those who did not $(P<0.05)$. Witnessing ischemic events did not affect their practice ( $25 \%$ vs $26 \%$ ). Other factors such as age, duration of practice, number of procedures performed per week, and patient setting (inpatient vs ambulatory) did not significantly impact their practice. Further, on multivariate analysis, endoscopists using their own experience were three times more likely to withhold all APT compared to those who did not $(P<0.05)$.

\begin{tabular}{|c|c|}
\hline Factors & Number (Percentage) \\
\hline Patient factors (previous bleed/ischemia) & $113(47)$ \\
\hline ASGE guidelines in high risk procedures & $99(41)$ \\
\hline ASGE guidelines all the time & $71(30)$ \\
\hline Own experience & $39(16)$ \\
\hline Setting (Inpatient/Ambulatory) & $16(7)$ \\
\hline Other factors & $3(1)$ \\
\hline Total & 239 \\
\hline
\end{tabular}


Table 2 Factors influencing withholding all antiplatelet agents before all procedures.

\begin{tabular}{|c|c|c|c|c|c|c|}
\hline Factor (respondents) & Number (\%) & Hold all (\%) & $\begin{array}{l}\text { Univariate OR } \\
\text { (95\% CI) }\end{array}$ & $\begin{array}{l}P \text { value } \\
\text { (univariate) }\end{array}$ & $\begin{array}{l}\text { Multivariate OR } \\
(95 \% \mathrm{Cl})\end{array}$ & $\begin{array}{l}P \text { value (mul- } \\
\text { tivariate) }\end{array}$ \\
\hline Age (239) & & & $1.6(0.8-3.4)$ & NS & & \\
\hline $30-40$ & $26(11)$ & $4(16)$ & & & & \\
\hline $41-50$ & $69(29)$ & $14(21.2)$ & & & & \\
\hline $51-60$ & $98(41)$ & $27(28.4)$ & & & & \\
\hline $61-70$ & $42(18)$ & $12(32.4)$ & & & & \\
\hline$>71$ & $4(2)$ & $2(50)$ & & & & \\
\hline Duration of practice (239) & & & $1.1(0.9-1.4)$ & 0.08 & & 0.86 \\
\hline$<5$ & $18(8)$ & $2(11.8)$ & & & 1 (ref group) & \\
\hline $5-10$ & $33(14)$ & $10(32.3)$ & & & $3.5(0.6-19.1)$ & \\
\hline $11-15$ & $40(17)$ & $12(30.8)$ & & & $2.7(0.5-14.2)$ & \\
\hline $16-20$ & $38(16)$ & $4(10.8)$ & & & $0.8(0.1-5)$ & \\
\hline$>20$ & $110(46)$ & $31(30.1)$ & & & $2.6(0.5-12.3)$ & \\
\hline Procedures performed per week (236) & & & $0.9(0.7-1.2)$ & NS & & \\
\hline $10-20$ & $34(14.4)$ & $11(32.3)$ & & & & \\
\hline $21-30$ & $79(33.5)$ & $19(24)$ & & & & \\
\hline $31-40$ & $62(26.3)$ & $14(22.5)$ & & & & \\
\hline$>40$ & $61(25.8)$ & $15(24.6)$ & & & & \\
\hline Own experience (227) & $\begin{array}{l}18 / 39(46) \text { vs } \\
41 / 188(22)\end{array}$ & & $3(1.5-6.3)$ & 0.002 & $3(1.4-6.2)$ & 0.003 \\
\hline Setting Ambulatory or Inpatient (239) & & $\begin{array}{l}4 / 16(25) \text { vs } \\
55 / 223(25)\end{array}$ & $0.9(0.3-3)$ & NS & & \\
\hline Witnesses ischemic complications (220) & & $\begin{array}{l}19 / 75(25) \text { vs } \\
38 / 145(26)\end{array}$ & $1(0.5-1.9)$ & NS & & \\
\hline $\begin{array}{l}\text { Witnessed bleeding with continuing any } \\
\text { anti-platelet agent (227) }\end{array}$ & & $\begin{array}{l}46 / 153(30) \text { vs } \\
13 / 74(18)\end{array}$ & $2(1-4)$ & 0.04 & $1.9(0.96-3.9)$ & 0.058 \\
\hline
\end{tabular}

Table 3 Procedures performed while on anti-platelet agent among endoscopists who did not hold all antiplatelet therapy.

\begin{tabular}{|l|l|}
\hline Procedure (respondents) & $\begin{array}{l}\text { Endoscopists performing } \\
\text { the procedure (\%) }\end{array}$ \\
\hline EGD (179) & $169(94)$ \\
\hline Diagnostic colonoscopy (186) & $181(97)$ \\
\hline ERCP (94) & $68(72)$ \\
\hline EUS (31) & $26(84)$ \\
\hline Colonoscopy with polypectomy (150) & $90(60)$ \\
\hline ERCP with sphincterotomy (94) & $30(32)$ \\
\hline Esophageal dilation (149) & $68(46)$ \\
\hline EUS with FNA (30) & $9(30)$ \\
\hline PEC (142) & $64(45)$ \\
\hline
\end{tabular}

Abbreviations: EGD, esophagogastroduodenoscopy; ERCP, endoscopic retrograde cholangiopancreatography; EUS, endoscopic ultrasound; FNA, fine needle aspiration; $\mathrm{PEG}$, percutaneous endoscopic gastrostomy

\section{Procedures performed while on antiplatelet agents}

Endoscopists who did not withhold all APT before procedures were asked about the procedures they performed while the patient was on APT ( $\bullet$ Table 3 ). Most of the endoscopists performed low risk procedures, esophagogastroduodenoscopy (EGD; 95\%), diagnostic colonoscopy (97\%), endoscopic ultrasound (EUS; 84\%), and endoscopic retrograde cholangiopancreatography (ERCP; 72\%). Among high risk procedures on APT, 60\% of endoscopists performed colonoscopy with polypectomy, $32 \%$ performed ERCP with sphincterotomy, 46\% performed esophageal dilation, 30\% performed EUS with fine needle aspiration (FNA) and $45 \%$ performed percutaneous enterogastric tube (PEG) placement. As expected, significantly higher numbers of endoscopists $(P<0.05)$ continued APT for low risk procedures (90\%) than for high risk procedures (47\%).
Use of APT with high risk procedures

We examined the use of APT with high risk procedures ( $\bullet$ Table 4). Approximately one-half of the respondents did not perform high risk procedures when their patients were on aspirin or NSAIDs although the guidelines state that they may be continued. Approximately, one-fourth of the respondents continued both aspirin and dipyridamole. Most respondents did not perform high risk procedures while their patients were on a combination or clopidogrel and a combination of either aspirin or NSAIDs.

\section{Restarting APT after high risk procedures}

Endoscopists were asked when they resumed use of antiplatelet agents in patients undergoing various procedures ( $\bullet$ Table 5 ). Most endoscopists (70\%) resumed use of antiplatelet agents on the same day after endoscopic biopsy and the others resumed use after $1-3$ days ( $25 \%$ ) or $3-5$ days (6\%). After endoscopic polypectomy, 79 (45\%) of the endoscopists resumed antiplatelet agents after 3-5 days compared to 61 (35\%) who restarted them in 1-3 days and $36(21 \%)$ who resumed use the same day. After esophageal dilation, half of the endoscopists resumed antiplatelet agents in 1-3 days and one-fourth of them each resumed APT either the same day or in 3-5 days. Similar to polypectomy, most endoscopists (52\%) resumed APT after ERCP and sphincterotomy in 3-5 days. Finally, after EUS and FNA, most endoscopists (46\%) resumed APT in 3-5 days. Factors such as age, type of hospital, number of years in practice, number of procedures performed, or witnessing ischemic events and bleeding complications did not influence adherence to guidelines. 
Table 4 Use of individual drugs with high risk procedures.

\begin{tabular}{|lllll|}
\hline Procedure & On ASA/NSAIDs (\%) & $\begin{array}{l}\text { On ASA and } \\
\text { dipyridamole (\%) }\end{array}$ & $\begin{array}{l}\text { On either ASA/ } \\
\text { clopidogrel (\%) }\end{array}$ & $\begin{array}{l}\text { On clopidogrel \& ASA/ } \\
\text { NSAIDS (\%) }\end{array}$ \\
\hline Colonoscopy with polypectomy & $139 / 238(58.4)$ & $71 / 238(29.8)$ & $54 / 238(22.7)$ & $28 / 238(11.8)$ \\
\hline Esophageal dilation & $106 / 237(44.7)$ & $50 / 237(21.1)$ & $40 / 237(16.9)$ & $21 / 237(8.9)$ \\
\hline PEG & $108 / 210(50.9)$ & $47 / 210(22.2)$ & $35 / 210(16.5)$ & $15 / 210(7.1)$ \\
\hline ERCP and sphincterotomy & $61 / 140(45.6)$ & $26 / 140(18.6)$ & $12 / 140(8.6)$ & $4 / 140(2.9)$ \\
\hline EUS with FNA & $9 / 20(45)$ & $5 / 20(25)$ & $3 / 20(15)$ & $2 / 20(10)$ \\
\hline Overall & $50 \%$ & $23.6 \%$ & $17 \%$ & $8.3 \%$ \\
\hline
\end{tabular}

Abbreviations: ASA, aspirin; NSAID, non-steroidal anti-inflammatory drugs; ERCP, endoscopic retrograde cholangiopancreatography; EUS, endoscopic ultrasound; FNA, fine needle aspiration; PEG, percutaneous endoscopic gastrostomy

Table 5 Days before endoscopists started antiplatelet agents after endoscopic procedures.

\begin{tabular}{|lll|}
\hline Procedure (respondents) & Days & Endoscopists (\%) \\
\hline Endoscopic biopsy (112) & Same day & $85(70)$ \\
& $1-3$ days & $30(25)$ \\
& $3-5$ days & $7(6)$ \\
\hline Polypectomy (176) & Same day & $36(21)$ \\
& $1-3$ days & $61(35)$ \\
\hline Esophageal dilation (174) & $3-5$ days & $79(45)$ \\
\hline ERCP with sphincterotomy (134) & Same day & $42(24)$ \\
& $1-3$ days & $87(50)$ \\
& $3-5$ days & $45(26)$ \\
\hline EUS with FNA (39) & $1-3$ days & $16(12)$ \\
& $3-5$ days & $69(37)$ \\
\hline & Same day & $7(18)$ \\
\hline
\end{tabular}

Abbreviations: ERCP, endoscopic retrograde cholangiopancreatography; EUS, endoscopic ultrasound; FNA, fine needle aspiration

\section{Discussion}

The ASGE guidelines divide procedures into low and high risk depending upon the risk of bleeding. Diagnostic endoscopy (EGD, colonoscopy, and sigmoidoscopy) with or without biopsy, ERCP without sphincterotomy, and EUS without FNA are among the low risk procedures. The ASGE recommends continuing aspirin and NSAIDs for all such procedures. For high risk procedures, the endoscopist may choose to withhold aspirin or NSAIDs 5-7 days before the procedure depending on underlying patient factors. In patients with acute coronary syndrome taking ticlopidine and clopidogrel, elective procedures must be deferred until they have received APT for the minimum recommended duration after which endoscopy is recommended after ceasing their administration for 7-10 days. Ticlopidine and clopidogrel may be continued with low risk procedures; cessation is recommended 7 - 10 days prior to high risk procedures. Further, the ASGE does not have clear consensus recommendations on restarting APT after an endoscopic procedure [12]. In our study, only $30 \%$ of endoscopists strictly adhered to published ASGE guidelines. Further, one-fourth of them fourth withheld APT regardless of the procedure risk, their practice driven by their own experience rather than the guidelines. Those using their own experience did not witness more ischemic or bleeding complications, were not significantly older, and had not performed more procedures than those who followed the guidelines. This shows that the use of the endoscopist's own experience is based on anecdotal rather than real evidence.
Although guidelines are not perfect and each endoscopist is encouraged to make decisions based on the clinical situation, some practices demonstrated in this survey were of little use. Approximately, one-fourth of the endoscopists withhold all anticoagulation regardless of the procedure and this exposes patients to unnecessary thromboembolic risk. One-half of the endoscopists surveyed withheld NSAIDs before a high risk procedure although the risk of bleeding is not increased [6-9,13-15]. Similarly, when biopsy is performed, antiplatelet agents can be resumed the same day regardless of the procedure.

Several large studies have demonstrated the safety of diagnostic endoscopy while using APT [19-22]. In a study by Basson et al [16], although colonic mucosal bleeding time was significantly elevated in patients on APT, there were no clinical consequences. A prospective randomized study by Whitson et al [17] showed that there was no attributable risk of bleeding after endoscopic biopsy among patients randomized to aspirin or clopidogrel. Studies that have assessed the risk of post-polypectomy bleeding indicate that aspirin does not increase this risk $[6-8,14,15,18]$. However, the opinion on delayed post-polypectomy bleeding is divided with Singh et al [8] showing a significant difference in delayed (3.5\% vs $1 \%$ ) bleeding while Feagins et al [15] did not. With other high risk procedures the data available are scarce. While Hui et al showed that aspirin was associated with increased post sphincterotomy hemorrhage [19], others [20,21] found no significant association. The only prospective study measuring the impact of APT on EUS with FNA showed no significant difference in bleeding between those taking aspirin and NSAIDs and controls [13]. While no significant bleeding complications were noted in several studies of esophageal dilation [22-25], there have been no published studies measuring the impact of APT on bleeding associated with esophageal dilation. Finally, three studies measuring the risk of bleeding on patients undergoing PEG showed no difference among patients on APT compared to controls [26-28]. Therefore, the variation found in the management of high risk procedures in this study is probably due to the divergent evidence regarding the same.

Two studies previously evaluated the practice patterns among endoscopists in the US. The first survey was done by Kadakia et al in 1996 [10]. While in our study $68 \%$ of endoscopists continued APT for diagnostic endoscopy, in the survey by Kadakia et al, only $40 \%$ did so. Similarly, only $19-49 \%$ and $21-25 \%$ of endoscopists continued APT before diagnostic colonoscopy and ERCP compared to $70 \%$ and $68 \%$, respectively, in the current study. The results of our study are similar to that of Lee et al [29] who compared the practice among eastern and western endoscopists. In their survey, $69 \%$ of the western endoscopists performed diagnostic EGD on APT compared to $68 \%$ in the current study. Similarly, $40-42 \%$ performed polypectomy while on APT compared to $43 \%$ in our 
study. They reported that $67 \%$ of endoscopists surveyed followed ASGE guidelines routinely while only $30 \%$ of the endoscopists our study followed ASGE guidelines all the time. While some of the difference in response may be due to differently worded questions, we believe fewer respondents in our study followed guidelines as prescribed.

Attempts should be made to improve physician adherence to guidelines. In addition to focused teaching sessions during conferences, computer or paper-based reminders of key points should be used to reinforce good practices. The use of blogs, websites, and social media platforms should be considered to reach out to those who do not regularly attend conferences. Apart from physicians, endoscopy nurses and patients must be educated about the use of these drugs in the peri-endoscopic period.

A strength of our study was the high response rate $(60 \%)$ to the survey. Response rates to similar surveys conducted previously have ranged between $<3 \%$ to $28.3 \%$ [16-18]. We attribute this difference to distributing paper-based survey questionnaires directly to members who attended conferences. The study results potentially apply nationwide as the participants generally came from various parts of the country. There are several limitations to this study. The survey was conducted among participating endoscopists at two national meetings, which may not represent all practice regions of the United States. Because participation in the study was voluntary, the study respondents may differ from nonrespondents. We do not have information on the people who chose not to respond to the survey. Although probing questions regarding the management of APT were asked, the responses may be skewed toward adherence to guidelines. Although the survey was developed and pretested by three experienced gastroenterologists based on available guidelines and prior published surveys, it is not validated outside the institution.

The results of this study indicate that there was poor uptake of ASGE's APT management guidelines among endoscopists in the US. Although some variation in the practice is acceptable, our guidelines indicate inappropriate withholding of APTs before procedures and reluctance to resume them later. An effort must be made to ensure close adherence to guidelines.

\section{Competing interest: None}

\section{Institutions}

${ }^{1}$ University of Kansas Medical Center, Gastroenterology, Kansas, City, Kansas, United States

${ }^{2}$ Kansas City Veterans Administration Medical Center, Gastroenterology, Kansas, City, Kansas, United States

${ }^{3}$ University of Genova, Dipartimento di Medicina Interna e Specialità Mediche, Genova, Italy

${ }^{4}$ Loyola University Medical Center, Gastroenterology, Chicago, Illinois, United States

${ }^{5}$ Washington University School of Medicine, Gastroenterology, St Louis, Missouri, United States

${ }^{6}$ Sansum Clinic, Gastroenterology, Santa Barbara, California, United States

\section{References}

1 Kaufman DW, Kelly JP, Rosenberg $L$ et al. Recent patterns of medication use in the ambulatory adult population of the United States: the Slone survey. JAMA 2002; 287: 337-344

2 Jain A, Pokharna R, Eghtesad B et al. Steroid withdrawal under tacrolimus for primary biliary cirrhosis, primary sclerosing cholangitis and autoimmune hepatitis after liver transplantation and long-term survival. Transplantation proceedings 2002; 34: 1524-1525

3 Pearson TA, Blair SN, Daniels SR et al. AHA Guidelines for Primary Prevention of Cardiovascular Disease and Stroke: 2002 Update: Consensus Panel Guide to Comprehensive Risk Reduction for Adult Patients Without Coronary or Other Atherosclerotic Vascular Diseases. American
Heart Association Science Advisory and Coordinating Committee. Circulation 2002; 106: 388 - 391

4 Sanchez DR, Diez Roux AV, Michos ED et al. Comparison of the racial/ ethnic prevalence of regular aspirin use for the primary prevention of coronary heart disease from the multi-ethnic study of atherosclerosis. Am J Cardiol 2011; 107: $41-46$

5 Paulose-Ram R, Hirsch R, Dillon C et al. Frequent monthly use of selected non-prescription and prescription non-narcotic analgesics among U.S. adults. Pharmacoepidemiol Drug Saf 2005; 14: 257-266

6 Shiffman ML, Farrel MT, Yee YS. Risk of bleeding after endoscopic biopsy or polypectomy in patients taking aspirin or other NSAIDS. Gastrointest Endosc 1994; 40: 458 - 462

7 Hui AJ, Wong RM, Ching JY et al. Risk of colonoscopic polypectomy bleeding with anticoagulants and antiplatelet agents: analysis of 1657 cases. Gastrointest Endosc 2004; 59: 44-48

8 Singh M, Mehta N, Murthy UK et al. Postpolypectomy bleeding in patients undergoing colonoscopy on uninterrupted clopidogrel therapy. Gastrointest Endosc 2010; 71: 998-1005

9 Manocha $D$, Singh $M$, Mehta $N$ et al. Bleeding risk after invasive procedures in aspirin/NSAID users: polypectomy study in veterans. Am J Med 2012; 125: 1222 - 1227

10 Kadakia SC, Angueira CE, Ward JA et al. Gastrointestinal endoscopy in patients taking antiplatelet agents and anticoagulants: survey of ASGE members. American Society for Gastrointestinal Endoscopy. Gastrointest Endosc 1996; 44: 309-316

11 Zuckerman MJ, Hirota WK, Adler DG et al. ASGE guideline: the management of low-molecular-weight heparin and nonaspirin antiplatelet agents for endoscopic procedures. Gastrointest Endosc 2005; 61: $189-194$

12 Anderson MA, Ben-Menachem T. AGSE Standards of Practice Committee. et al. Management of antithrombotic agents for endoscopic procedures. Gastrointest Endosc 2009; 70: 1060-1070

13 Kien-Fong $\mathrm{Vu}$ C, Chang F, Doig $L$ et al. A prospective control study of the safety and cellular yield of EUS-guided FNA or Trucut biopsy in patients taking aspirin, nonsteroidal anti-inflammatory drugs, or prophylactic low molecular weight heparin. Gastrointest Endosc 2006; 63: $808-813$

$14 \mathrm{Kim}$ HS, Kim TI, Kim WH et al. Risk factors for immediate postpolypectomy bleeding of the colon: a multicenter study. Am J Gastroenterol 2006; 101: $1333-1341$

15 Feagins LA, Uddin FS, Davila RE et al. The rate of post-polypectomy bleeding for patients on uninterrupted clopidogrel therapy during elective colonoscopy is acceptably low. Dig Dis Sci 2011; 56: 2631 2638

16 Basson MD, Panzini L, Palmer RH. Effect of nabumetone and aspirin on colonic mucosal bleeding time. Aliment Pharmacol Ther 2001; 15: $539-542$

17 Whitson MJ, Dikman AE, von Althann C et al. Is gastroduodenal biopsy safe in patients receiving aspirin and clopidogrel? A prospective, randomized study involving 630 biopsies. J Clin Gastroenterol 2011; 45: $228-233$

18 Sawhney MS, Salfiti N, Nelson DB et al. Risk factors for severe delayed postpolypectomy bleeding. Endoscopy 2008; 40: 115-119

19 Hui CK, Lai KC, Yuen MF et al. Does withholding aspirin for one week reduce the risk of post-sphincterotomy bleeding? Aliment Pharmacol Ther 2002; 16: 929-936

20 Hussain N, Alsulaiman R, Burtin P et al. The safety of endoscopic sphincterotomy in patients receiving antiplatelet agents: a case-control study. Aliment Pharmacol Ther 2007; 25: 579-584

21 Freeman ML, Nelson DB, Sherman S et al. Complications of endoscopic biliary sphincterotomy. N Engl J Med 1996; 335: 909-918

22 Pereira-Lima JC, Ramires RP, Zamin IJr et al. Endoscopic dilation of benign esophageal strictures: report on 1043 procedures. Am J Gastroenterol 1999; 94: 1497-1501

23 Raymondi R, Pereira-Lima JC, Valves A et al. Endoscopic dilation of benign esophageal strictures without fluoroscopy: experience of 2750 procedures. Hepatogastroenterology 2008; 55: $1342-1348$

24 Polese L, Angriman I, Bonello E et al. Endoscopic dilation of benign esophageal strictures in a surgical unit: a report on 95 cases. Surg Laparosc Endosc Percutan Tech 2007; 17: 477-481

25 Williams VA, Watson TJ, Zhovtis $S$ et al. Endoscopic and symptomatic assessment of anastomotic strictures following esophagectomy and cervical esophagogastrostomy. Surg Endosc 2008; 22: 1470-1476 
26 Ruthmann O, Seitz A, Richter S et al. [Percutaneous endoscopic gastrostomy. Complications with and without anticoagulation]. Chirurg 2010; 81: $247-254$

27 Jalal PK, Hall M, DavidoffS et al. Does Aspirin Increase the Risk of Bleeding for Percutaneous Endoscopic Gastrostomy Procedure? Gastrointest Endosc 2006; 63: AB107
28 Richter JA, Patrie JT, Richter RP et al. Use of High-Dose Aspirin or Clopidogrel Before or After Percutaneous Endoscopic Gastrostomy Is Not Associated With Post-Procedural Bleeding. Gastrointest Endosc 2010; 71: AB114

29 Lee SY, Tang SJ, Rockey DC et al. Managing anticoagulation and antiplatelet medications in gastrointestinal endoscopy: a survey comparing the East and the West. Gastrointest Endosc 2008; 67: 1076-1081

\section{Supplement}

online content viewable at: www.thieme-connect.de 